\title{
Efficacy of analgesia nociception index monitoring for procedural sedation and analgesia in adult patients
}

\author{
Soral M.1, Tore Altun G.2 ${ }^{2}$ Corman Dincer P.1, Arslantaş M.K.ㄹ, Aykac Z.1 \\ ${ }^{1}$ Marmara University School of Medicine, Dept of Anaesthesiology \& Intensive Care, Istanbul, Turkey \\ 2Marmara University Pendik Training and Research Hospital, Dept of Anaesthesiology \& Intensive \\ Care, Istanbul, Turkey
}

\section{Background}

Hypnosis, analgesia and immobility constitute three components of anaesthesia. To assess analgesia objectively Analgesia Nociceptive Index (ANI) monitoring can be used. Measurements are continuously done according to heart rate variability. A value between 50-70 is aimed under general anaesthesia for ideal nociception/antinociception balance (I).

The aim of the study was to investigate the efficacy of ANI monitoring for procedural sedation and analgesia for maintaining rational drug use and patient safety.

\section{Methods}

After ethics approval and informed consent 102 patients between 18-70 years of age, scheduled for elective colonoscopy under sedation are prospectively analysed. After induction with propofol and ketamine; infusions of propofol $\left(2 \mathrm{mg} \cdot \mathrm{kg}^{-1} \cdot \mathrm{h}^{-1}\right)$ and remifentanil $\left(0.05 \mathrm{mcg} . \mathrm{kg}^{-}\right.$ '. $\left.\mathrm{min}^{-1}\right)$ were started. Patients were randomised according to having ANI monitored (Group A) or not (Group K). In group A remifentanil infusions were titrated to maintain ANI value between $50-70$, in group $\mathrm{K}$ analgesic (i.e. remifentanil) requirements were met according to attending anaesthetist's intention. Heart rate, blood pressure, respiratory rate, $\mathrm{SpO}_{2}, \mathrm{BIS}, \mathrm{NRS}$ (Numeric Rating Scale), RSS (Ramsay Sedation Scale) in all patients and ANI in group A were monitored. Complications, total analgesics used, duration of the procedure, demographic information and in the recovery period NRS and MAS (Modified Aldrete Score) were evaluated. Data were analysed with Student's $t$ test or Mann-Whitney $U$ test depending on the normality of distribution. Qualitative data were analysed with Pearson chi-square test. A P-value of $<0.05$ was considered statistically significant.

References:

1- Boselli E, Daniela-Ionescu M, Begou G, Bouvet L, Dabouz R, Magnin C, et al. Prospective observational study of the noninvasive assessment of immediate postoperative pain using the analgesia/nociception index (ANI). British journal of anaesthesia. 2013;111(3):453-9.

\section{ANI Monitor}
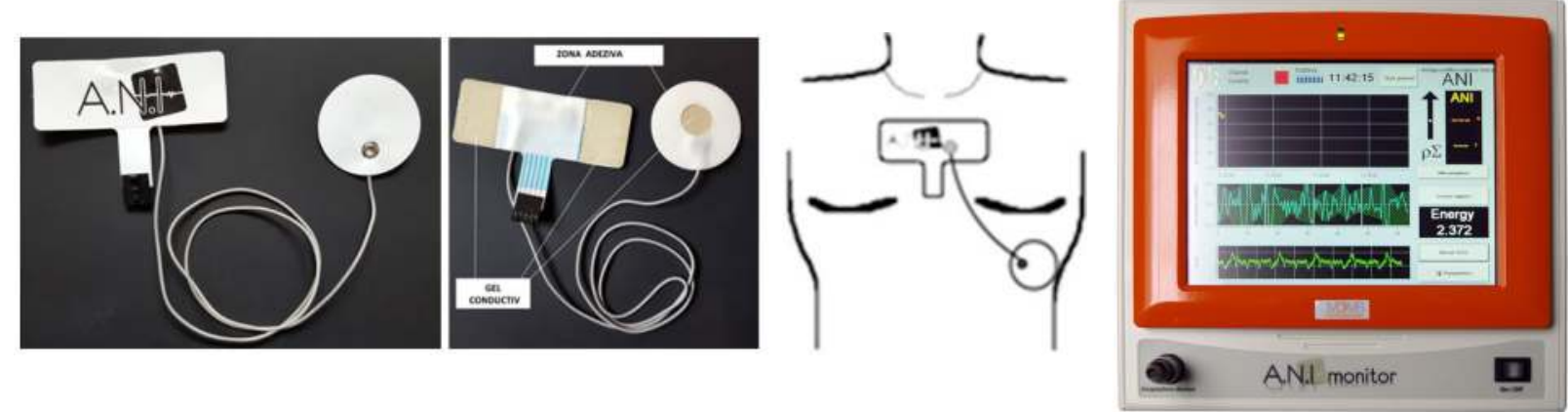

\section{Results}

Between the groups demographic parameters were similar and no statistical difference was found in heart rate, blood pressure, recovery times and complications $(p>0.05)$. Total remifentanil amount used was statistically low in group $A(p: 0.01 \mathrm{l})$.

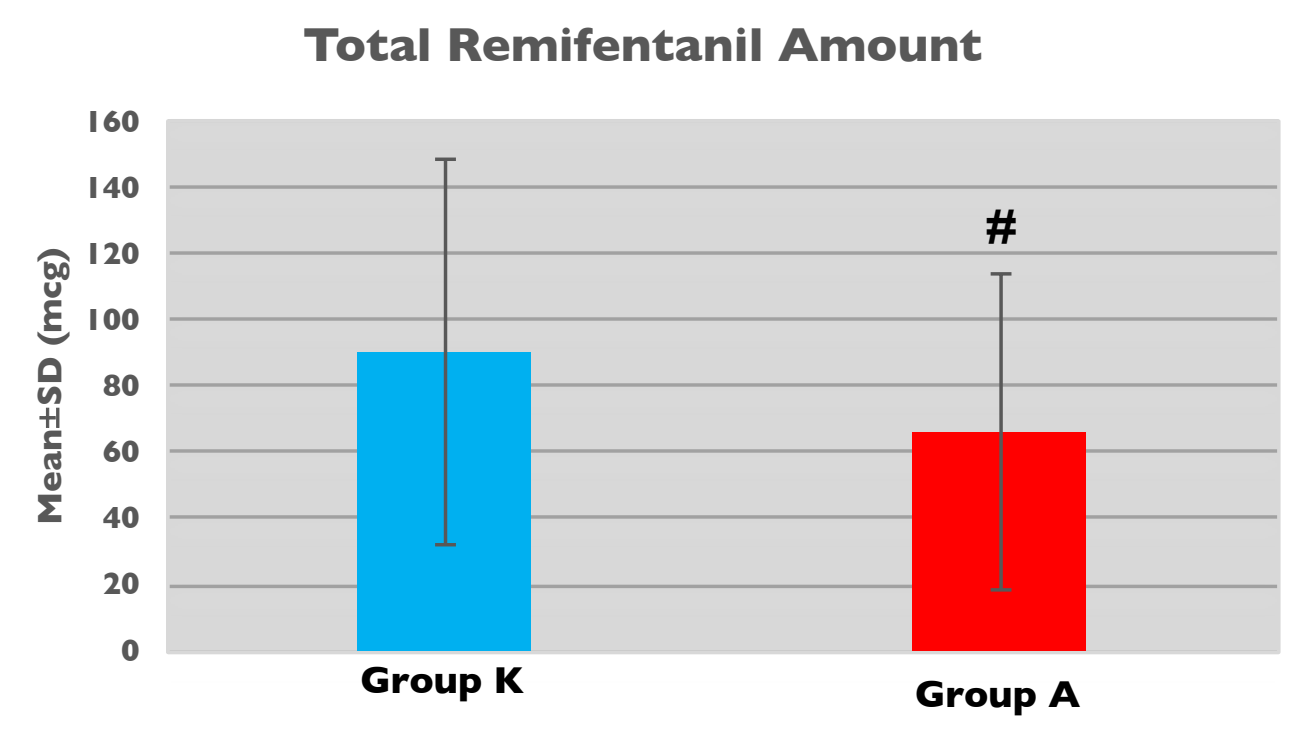

\section{Conclusions}

The efficacy of ANI monitoring during procedural sedation is yet to be evaluated. We demonstrated that opioid consumption was diminished when ANI monitoring was used, thus patient safety was ameliorated. Although side effects and recovery times were not significantly different between the groups, we believe further studies with longer procedure times are needed to demonstrate if a difference exists in these parameters.
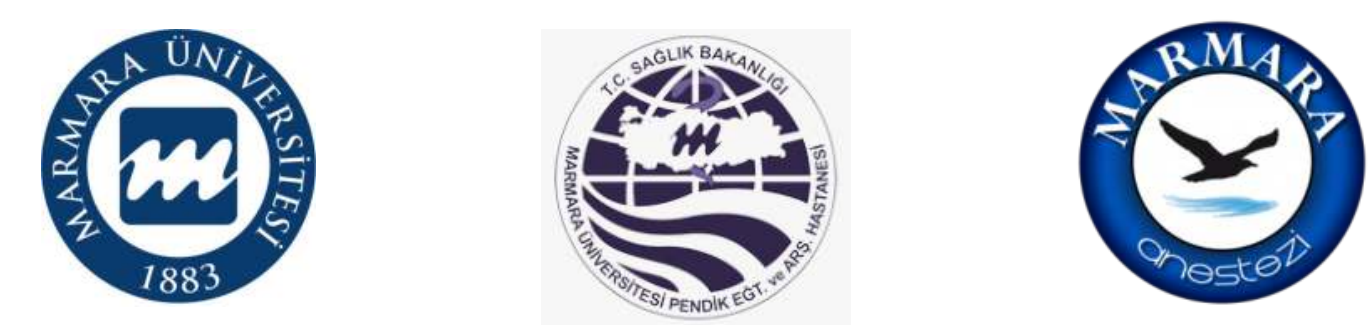